\title{
KNOWLEDGE, ATTITUDE AND PERCEPTIONS OF VILLAGE RESIDENTS ON THE HEALTH RISKS POSED BY KADHODEKI DUMPSITE IN NAIROBI, KENYA \\ *NJAGI, J.M., ${ }^{\text {* IRERI, A.M.,2 }}$ NJAGI, E.N.M.,3 AKUNGA, D.,1AFULLO, A.T.0., ${ }^{4}$ NGUGI, M.P., 3 MWANZO, I. ${ }^{5}$ AND NJAGI I. K. ${ }^{6}$ \\ http://dx.doi.org/10.4314/ejesm.v6i4.12
}

Received 27th April 2013; accepted 4th July 2013

\begin{abstract}
This study sought to assess the knowledge, attitude and perceptions of the residents of Kadhodeki village on the health risks posed by the Kadhodeki dumpsite. Using households as units of sampling, a descriptive cross sectional survey was carried out in June 2012. Random data were collected using a face-to-face researcher administered structured questionnaire and 323 participants were interviewed. Chi square was used to determine the association between the different variables. Findings indicate that residents possess a significantly low knowledge and a positive attitude $(\chi 2(1)=$ $224.03, p<0.01 ; \chi 2(1)=8.697, p<0.01)$ towards the Kadhodeki dumpsite. They were however no differences in risk perceptions. Participant's age, duration one had lived in the village and their level of education, were proxy measures of knowledge, attitude and perception. Odds ratio analysis indicates that age and duration did not influence participant's knowledge, attitude or perceptions. Rudimentary however, education accounted for a non significant $28 \%$ variation in respondents' attitude towards the health risks of the dumpsite (OR=1.282; $\mathrm{Cl} 0.828-1.997)$. Also adequate education significantly accounted for $67 \%$ variation in respondents' health risk perception (OR= 1.671; Cl 1.304-2.140). This study would recommend that the ministry of Health come up with health education programmes for the general population on the dangers of uncontrolled waste disposal sites.
\end{abstract}

\section{Introduction}

Urban waste management is a global growing concern. Inadequate waste collection and disposal impact on the ecosystems of cities contribute to the degradation of the urban environment and pose a health hazard to urban populations at large. People living adjacent to improperly managed waste sites are affected the most due to the potential of the waste to pollute water, food sources, land, air and vegetation (UN-HABITAT, 2008).

According to World Health Organization (2006) it is estimated that about a quarter of diseases facing mankind today occur due to prolonged exposure to environmental pollution (Kimani, 2007; Prüss-Üstün and Corvalán, 2006). Issues related to the disposal of waste pose important challenges for many communities developed or otherwise. They affect not only the environment but also public health. While developed communities have established improved waste management strategies, dumpsites are a common eyesore in African cities (UNDP, 2006 ; Rotich et al., 2006).

${ }^{I}$ Department of Environmental Health, Kenyatta University, Nairobi, Kenya

${ }^{2}$ Department of Educational Psychology, Kenyatta University, Nairobi, Kenya

${ }^{3}$ Department of Biochemistry \& Biotechnology, Kenyatta University, Nairobi, Kenya

${ }^{4}$ Office of International programs, North Central College, Naperville 60540, Illinois, USA.

${ }^{5}$ Department of Community Health, Kenyatta University, Nairobi, Kenya

${ }^{6}$ Department of Education, Chuka University College, Chuka, Kenya.
Open dumps generate various environmental and health hazards since they are sites for unregulated and haphazard dumping of restricted materials such as car batteries, metals, pathological wastes and sharps from the nearby health facilities. Households and market wastes also contribute to open dumpsites (Agunwamba, 1998). The decomposition of waste materials in the sites produces methane, which may cause fire and explosions as well as pollute surface and ground water. Most of the dumpsites lack a soil cover which enable rainwater to infiltrate refuse and produce leachate that contaminates ground water reserves. Most of the waste is also easily blown away by the wind, making it an eyesore as plastics litter the area around the dump (Cointreau - Levine, 1997 ; Oyelola et al., 2009; Mangizvo, 2010)

Nairobi City faces numerous solid waste management challenges. Many of the city estates are littered with garbage which when collected eventually finds its way into open dumpsites (Rotich et al., 2006; Afullo and Odhiambo, 2009). At present approximately $32.3 \%$ of Kenya's population live in urban areas (KNBS, 2009). The increasing influx of rural people into the city without matched urban planning has 
continued to result in a wide variety of environmental problems (EMCA, 1999). Some of the problems include the current inability of urban authorities to adequately manage large quantities of the generated solid waste (UNDP, 2006). This has resulted to uncontrolled and unmonitored disposal of waste in open dumps with the consequence of contamination and subsequent pollution of the environment. This has become a global concern due to their widespread distribution and multiple effects on the ecosystem (Nriagu, 1990 ; Uwah et al., 2011).

Kadhodeki dumpsite started in 1986 as a way of filling in the large gaping man holes that had been left open after quarrying activities in the construction of Nairobi/ Waiyaki highway. The dumping of the waste was a way of the land owners making some money.

Very few studies have been conducted to establish the perceptions and attitude of people living near open dumpsites in Nairobi. Existing studies indicate that socio-economic characteristics like age, marital status, household size, education, occupation and length of stay an area are associated with people's knowledge, attitude and perception of health hazards (Olorunfemi, 2009). However, such studies are scanty particularly in Nairobi.

Against this background, this study was carried out to assess the knowledge, attitude and perception of community living around the Kadhodeki dumpsite in Nairobi, regarding the health risks posed by the site.

\section{Methodology \\ Study Location}

This study was carried out in Kadhodeki Village in, Waithaka Sublocation in Dagoretti Division, Nairobi County, Kenya. The village is home to Kadhodeki Dumpsite, an open dumpsite declared illegal by the Nairobi City Council. The coordinates for the study area are $1^{0} 16^{\prime} 31.58$ "S, $36^{\circ} 43$ '52.95" $\mathrm{E}$ (the red patch shows the area occupied by the dumpsite; all units are in square metres).

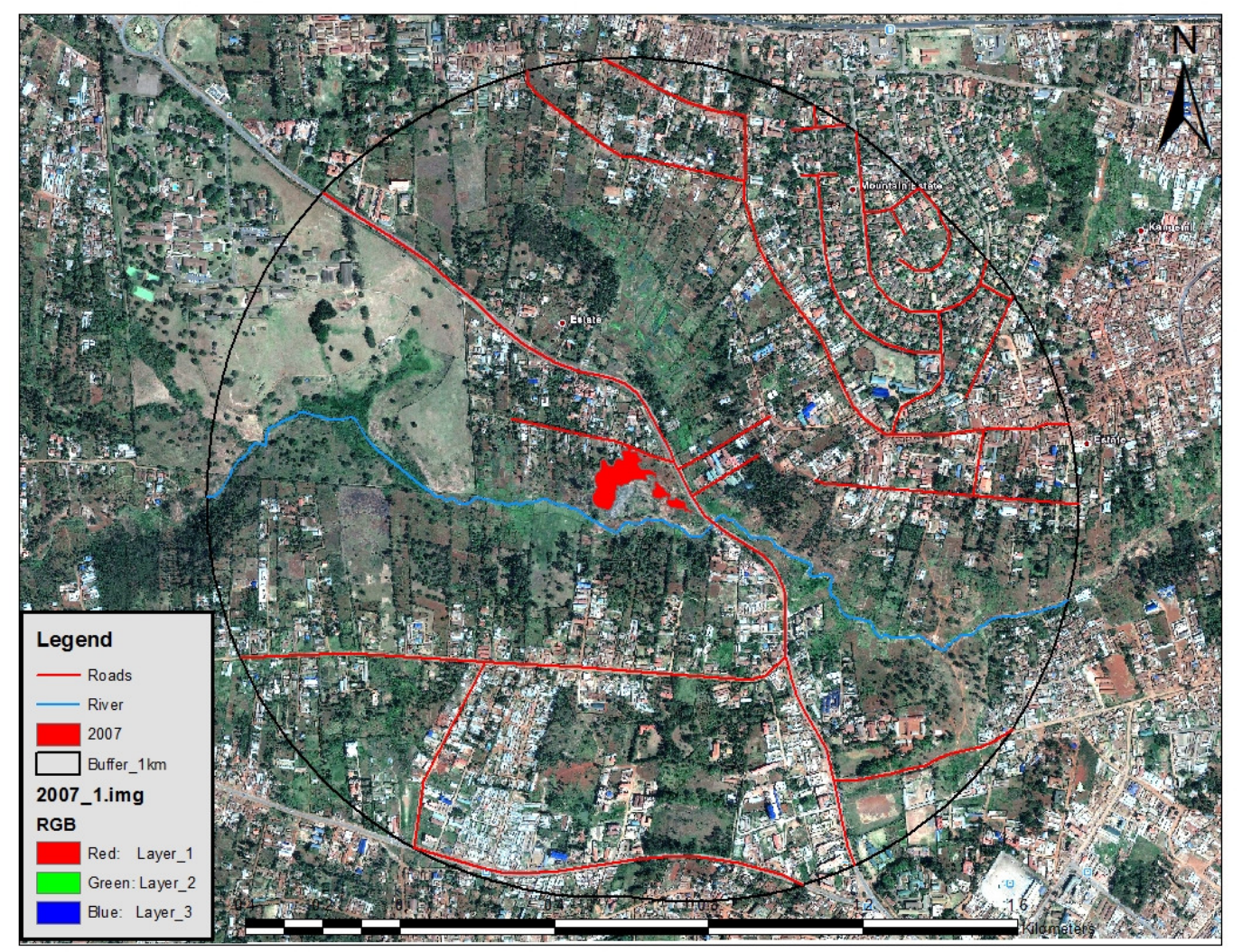

Study Populations

\section{Study Design}

A descriptive cross sectional survey was carried out to assess whether the people that live around the dumpsite are aware of the health risks posed by the site.
Using households as units of sampling, simple random sampling was used to select the study participants. Based on Fischer et al. (1989), a total of 179 female and 144 male participated in the study. 


\section{Data Collection and Analyses}

Data were collected using a pre-tested structured interviewer administered questionnaire. Data analysis was carried out using Predictive Analytic Software for windows (PASW version 19). Descriptive statistics such as frequencies and percentages were used to summarize the data in the questionnaires. Inferential statistics were made using Chi square to test for associations between the different independent variables and knowledge, attitude or perception of the respondents. Permission was sought from Kenyatta University Ethical Research Committee and the Ministry of Higher Education Science and Technology. Informed consent was sought from the individual participants after explaining to them the objective of the study. Confidentiality was ensured throughout the study.

\section{Results}

\section{Socio Demographic Data of the participants}

As presented in Table 1, the ages of the participants ranged between 18 to 83 years $(M$ $=35$ years; $S D=12.5$ ). Participants' level of education, number of years they had lived in the village were also assessed (Table 1). These factors were treated as proxy measures for knowledge, attitude and perception. The results presented in Table 1 indicate that most of the participants $(72.8 \%)$ had lived there for more than 5 years. Slightly, over half of the participants $(50.8 \%)$ had lived in the village for more than 10 years.

The study further sought to know the number of people living in the participants' households. This is important since the higher the number of persons living in a particular house the higher the amount of waste generated and dumped and the higher the number exposed to health risks associated with dumping. Results indicate that household size averaged 4 with a range of 1-10 persons. As well majority (70\%) of respondents were married (Table 1).

The study also sought to know if the participants were aware of the duration of time the dumpsite had been existence. This awareness is important since it may influence the participant's knowledge, attitude and perceptions of the health risks it poses. The results indicate that $44.9 \%$ of the participants did not know how old the dumpsite was. Among those who gave a positive answer only $23.8 \%$ of the participants were correct (Table 1). According to a village elder, the dumpsite was started in 1986 and at the time of the interview it was in its $26^{\text {th }}$ year of existence.

Knowledge, Attitude and Perception of the participants

The results show that an overwhelming majority of the participants $(91.6 \%)$ had inadequate knowledge while only $8.4 \%$ had adequate knowledge. Chi-square test results indicate that the participant's knowledge about the health risks posed by the dumpsite was indeed significantly low $\left(\chi^{2}(1)=224.03, p<\right.$ $0.01)$.

Slightly more than half $(58.2 \%)$ of the participants had a positive attitude towards the dumpsite while $41.8 \%$ had negative attitude. A Chi-square test was calculated comparing the frequency of participants with positive attitude and those with low attitude. A significant difference in the participants' attitude towards the dumpsite was found $\left(\chi^{2}(1)=8.697, \mathrm{p}<\right.$ $0.01)$.

Results show that $56.3 \%$ of the participants perceived themselves to be at a high health risk from the dumpsite while $43.7 \%$ viewed themselves to be at low risk. However, Chisquare test of independence indicate that the participants perception about the health risks posed by the dumpsite were not significantly different $\left(\chi^{2}(1)=3.793, p>0.01\right)$.

The research sought to know whether the age of the participant had any influence on ones knowledge, attitude and perception towards the Kadhodeki dumpsite. For this purpose age was quantified to two levels, those participants who were below 35 years were said not be old enough $184(57 \%)$ while those that were 35 years and above were said to be old enough 139 $(43 \%)$. The age of the participants was found not to affect the variables of knowledge, attitude and perceptions.

The level of education has been shown to influence the level of knowledge, attitude and perception of the participants (Kariyawasam et al., 2006). About half of the participants had inadequate education $(50.5 \%)$ and slightly less than half $(49.5 \%)$ had adequate education. Education was observed to account for $28 \%$ variation in attitude towards the health effects of the dumpsite among the participants which was however not significant as shown by analysis of odds ratio $(\mathrm{OR}=1.282$; CI $0.828-1.997)$. However, adequate education positively influenced high risk perception by $67 \%(\mathrm{OR}=$ 1.671; CI 1.304-2.140). Too few numbers on adequate knowledge limited the use of odds ratio 
Knowledge, Attitude and Perceptions of Village Residents on the Health Risk................NJAGI et al.

on analyzing the influence education had on knowledge.

The research also sought to find out whether the number of years one had lived in the village had any influence on knowledge, attitude and perception of the participants on the health risks posed by the dumpsite. For this purpose, participants who had live in the village for less than 10 years were grouped in one category 112 $(34.7 \%)$ and those who had lived in the village for more than 10 years were grouped in another 211 (65.3\%). Analyses using odds ratio revealed that the number of years the participant had lived in the village did not influence their knowledge, attitude and perception on the risks posed by the dumpsite $(\mathrm{OD}=0.871$; $\mathrm{CI}=0.686$ 1.106: $\mathrm{OD}=1.163 ; \mathrm{CI}=0.994-1.360: \mathrm{OD}=$ 0.982; CI=0.838-1.152) respectively.

\section{Self-reported Symptoms}

To be able to further explore the health risks posed by the dumpsite, the participants were asked to indicate whether they or members of their households had certain symptoms in the past six months. As shown in Figure 1, chest pain like symptom was replied by $28.5 \%$ followed by stomach problems $(23.2 \%)$ rashes, itching and or acne (19.2\%), chronic heart burn (16.7\%) persistent joint pain (14.5\%).

Table 1 Socio Demographic Data of respondents in Kadhodeki Village $(\mathrm{N}=323)$

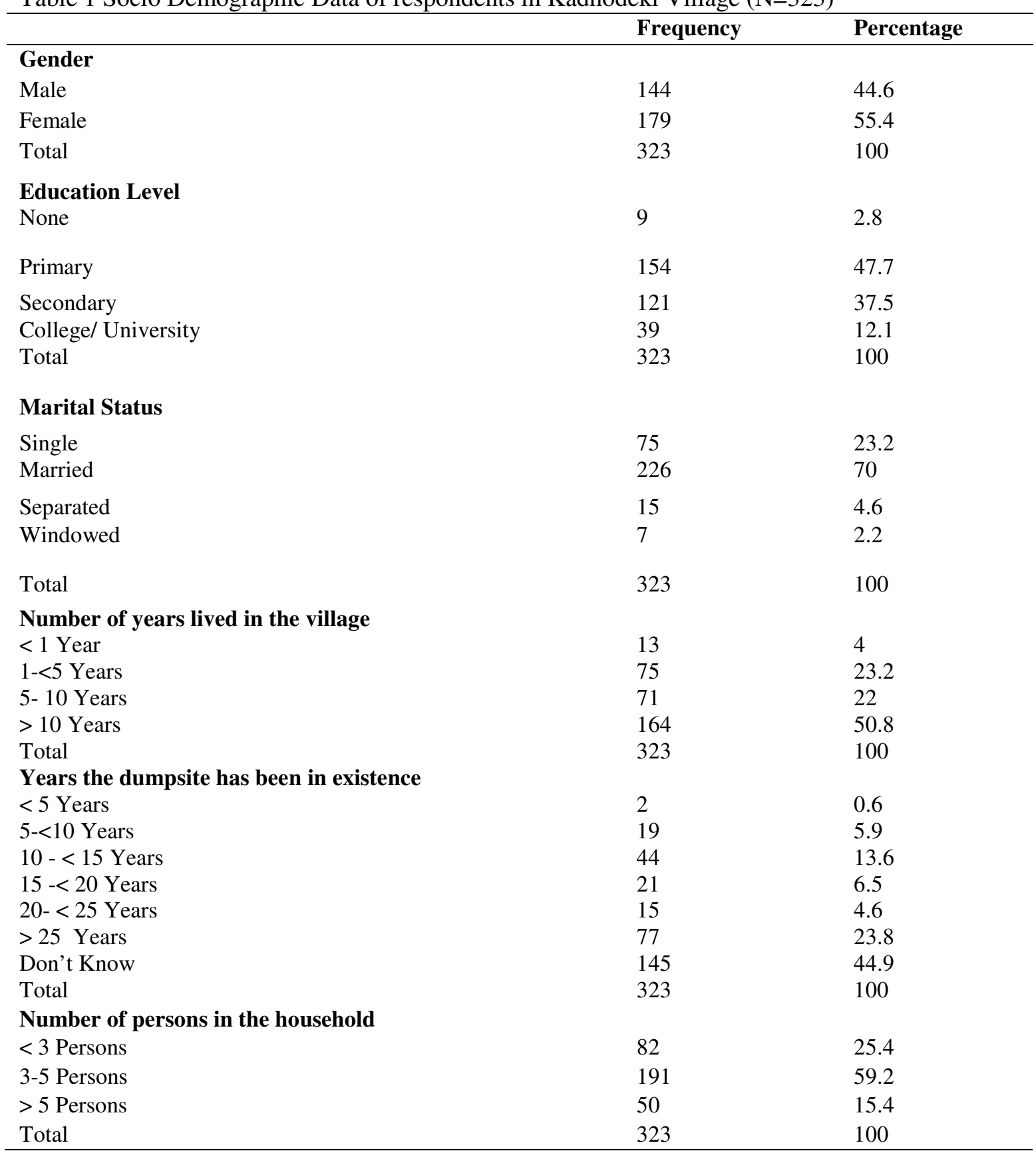




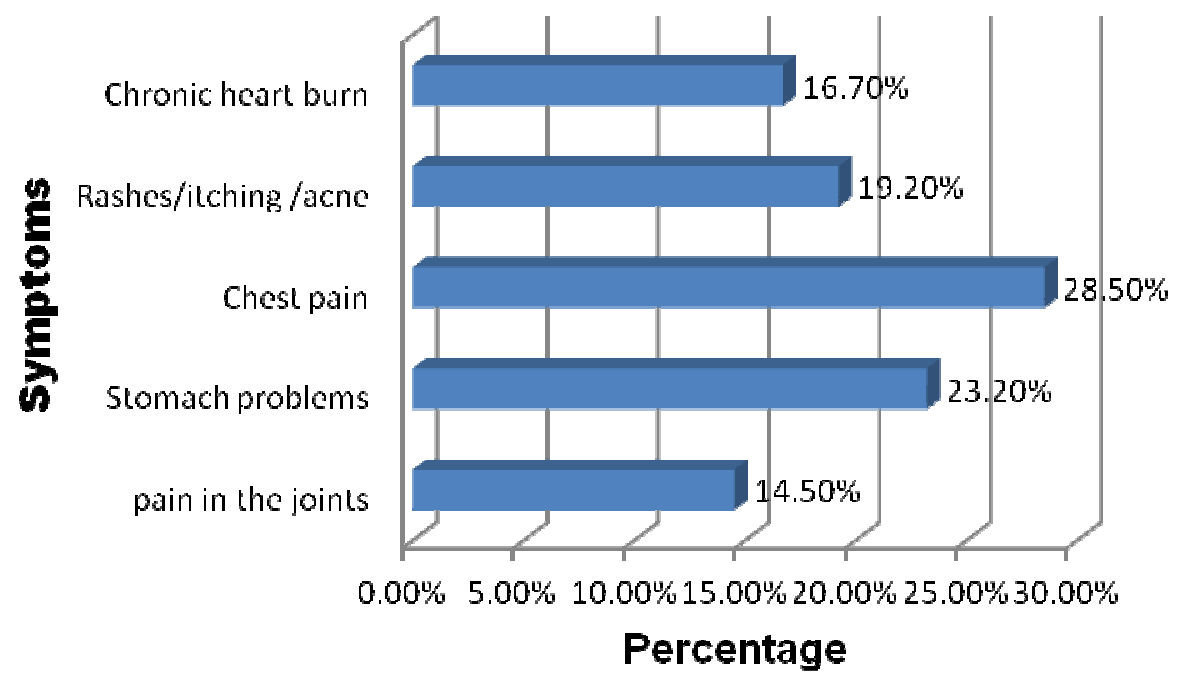

Figure 1 Symptoms with the highest percentage

The research further sought to quantify the self reported symptoms and further analysis of the scores revealed that $53.3 \%$ of the participants had self reported good health while $46.7 \%$ had poor health. The number of persons in the participants household was seen to positively influence the reported health outcomes of the participants $(\mathrm{OR}=2.391$; CI 1.525-3.751).

\section{Discussion}

Age did not statistically influence the participant's knowledge, attitude or perceptions of the health risks posed by the dumpsite. Studies done by Coffie (2010) and Grasmuck et al., (2005) reported similar findings.

Level of education has been shown to influence participant's knowledge, attitude and perceptions of different issues. Analysis of the level of education of the participants in this study indicate that almost half of participants had attained secondary education and above which is in line with Kenya demographic and health survey of 2008-2009 report that states that only $53 \%$ of the population have secondary education and above (KDHS, 2010).

In this study household size was reported at between 1 and 10 persons indeed, more than half of the households had at least four members. Household size was observed to increase the number of self reported health symptoms (OD = 1.607; $\mathrm{CI}=1.247-2.071)$. This finding agrees with Olorunfemi (2009) who reports that the more the number of people in the household the more people are at risk of suffering from the negative impact of the dumpsite. More than half of the participants had lived in the village for more than 5 years. It seems to be crucial since the dumpsite has been inexistence for several years; indeed the longer someone has been living in the contaminated area, the more likely it is that he or she suffers the associated health risks (Olorunfemi, 2009).

For this study any participant who had attained a primary level of education and below was treated as having inadequate education and any participant who had attained a secondary school level and above was treated as having an adequate level of education. The results of this study reveal that there is a significant relationship between the participants' education level and their knowledge on the health risks posed by the dumpsite. Indeed, Olorunfemi (2009) reports that high level of literacy is considered advantageous for the fact that knowledge plays a significant role in impact studies. Other studies have reported otherwise; a survey on secondary school teachers reported that they demonstrated a low level of environmental knowledge (Mansaray et al., 1998). On the other hand, participants' age and number of years they had lived in the village did not affect their knowledge on the health risks posed by the dumpsite.

The results of this study show that education had no association with what the participants felt were the risks posed by the dumpsite. These results are similar to findings by Mansaray et al., (1998) in a study done in Nigeria among 
secondary school teachers (who have a higher level of education than most members of a general population) where negative environmental attitudes were found to be prevalent among the three categories of teachers interviewed .

Similarly, the age and number of years the participant had lived in the village did not influence the participant's feelings on the dangers posed by the dumpsite. Though the factors mentioned above did not influence the participant's attitudes, the difference between those who had a positive attitude and those who had a negative attitude was significant.

The results indicate that the more educated the participants were, the more likely they were to perceive themselves at a high risk of the health risks posed by the dumpsite. This finding is congruent with earlier findings by Kariyawasam et al., (2006) who showed that the level of education had a significant association with consumer attitudes and perceptions. Similarly, Scholz and Weber (2001) show that the increase in knowledge through being given new information increases participants' risk ratings. However, a survey by Coffie (2010) showed that the participant's perception towards waste disposal issues was not influenced by their educational level, income or age. Indeed, the results of this study reveal that participants' age did not influence their perceptions.

The number of years the respondents had lived in the village did not influence their perception on the risks posed by the dumpsite. This is consistent with Grasmuck et al., (2005) who revealed an insignificant relationship between risk perception and the duration of the exposure. Though objectively, the people who have lived in the village for a long time are more at risk than others.

Health risk perception plays an ongoing role in the public response to environmental exposures (Dupler, 2001). Essentially, relationships between an environmental contaminant and health are mediated by perceptions of the 'exposure' which are in turn influenced by a host of individual and contextual factors (Ferner, 2001). The fact that more than half of the participants perceived themselves at high risk and that there was a significant association between education and perception may be because of the documentaries in TV stations about vegetables grown on raw sewage and the debates about relocations of Dandora dumpsite. Elliott (1998) reports that public opinion literature indicates that worries and concern about environmental and health has increased steadily over the past two decades and that the increase is associated with widely publicized environmental disasters.

Results indicate that the more the number of people in a household the more the self-reported symptoms. Indeed, Olorunfemi (2009) states that the more the number of people in the household the more at risk of suffering from the negative effects of the dumpsite. Similarly, the way the participants felt about the health risks posed by the dumpsites significantly influenced how they answered the question on self -reported symptoms.

Although biases and confounding factors cannot be excluded as explanations for these findings, the findings may indicate real risks associated with residence near certain landfill sites. An increase in self-reported health outcomes and symptoms has been found consistently in health surveys around sites where local concerns were evident (Zupancic, 1997). Similarly, to what Vrijheid (2000) reported, it is difficult to conclude whether these symptoms are an effect of direct toxicological action of heavy metals present in dumpsite, an effect of stress and fears related to the dumpsite, or an effect of reporting bias.

\section{Conclusion}

The people living in Kadhodeki village were found to have inadequate knowledge about the health risks posed by the site which was found to have a significant association with the level of education. On the other hand, factors such as the age of the participant and the number of years one had lived in the village were found not to influence ones knowledge. Slightly above half of the participants were found to have a positive attitude which was not influenced by their level of education, their age or the number of years they had lived in the village. Those who perceived themselves at high risk were more than half the number of participants and a significant association between level of education and perception was revealed. However, the age of the participant and the number of years he or she had lived in the village did not significantly influence their perceptions on the health risks posed by the dumpsite. The study also showed a significant relationship between the reported health status and the number of persons in the participant's household. 
This study and others have shown that the health risks associated with dumpsites are significant. The area used for dumping and in this case was easily accessible to people and especially children, who are vulnerable to the physical and chemical hazards posed by wastes. Rodents, insects, and other vermin attracted to dump sites may also pose health risks. The costs to local government and industry associated with cleaning up uncontrolled dumpsites are significant. Unfortunately, residents that dispose of their wastes in a responsible manner ultimately pay these costs.

\section{Acknowledgement}

Our gratitude goes to $\mathrm{Mr}$. Kangethe the village elder and Mrs. Lydia from the Ministry of Agriculture, Dagoretti Division, who accompanied us as we interviewed the residents of Kadhodeki. We sincerely thank the people of Kadhodeki Village who permitted us to interview them.

\section{References}

Afullo, O. A., and Odhiambo, F. (2009), The primary solid waste storage gaps experienced by Nairobi households. Ethiopian Journal of Environmental Studies and Management, 3(2), 34-43.

Agunwamba, J. C. (1998), Solid waste management in Nigeria: Problems and issues. Environmental Management, 25(2), 849-856.

Coffie, F. M. (2010), Landfill sites management challenges: the perceived effect and

willingness on the part of the people in the GA East and South municipalities to pay for improvement. Master of Science In Development Policy and Planning, Kwame Nkrumah University of Science and Technology Kumasi, College of Architecture and Planning.

Cointreau - Levine, S. (1997), Occupational and environmental health. Issues of solid waste management. Special emphasis on middle and lower income countries. World Bank Report.

Dupler, D. (2001), Heavy metal poisoning.: Farmington Hills, MI: Gale Group.

Elliott, S.J. (1998), "A Comparative Analysis of Public Concern over Solid Waste Incinerators". Waste Management and Research, 16 (4) 351 364.

EMCA. (1999). Environmental Management and Co-ordination Act. ACT NO. 8 of 1999

Ferner, D. J. (2001), Toxicity, heavy metals. eMedical journal, 2(5) 1
Grasmuck, D., Scholz, R., and Risk, W. (2005), Perception of Heavy Metal Soil Contamination by High-Exposed and Low-Exposed Inhabitants: The Role of Knowledge and Emotional concerns. Risk Analysis, 25(3), 611-622.

Kariyawasam, S., Jayasinghe-Mudalige, U. and Weerahewa, J. (2006), Assessing Consumer Attitudes and Perceptions Towards Food Quality: The Case of Consumption of TetraPacked Fresh Milk in Sri Lanka Montreal, Quebec, Canada: Canadian Agricultural Economics Society.

KDHS. (2010). 2008-09 Demographic and Health Survey. Key Findings. Kenya National Bureau of Statistics. Maryland USA

Kimani, N. G. (2007), Implications of the Dandora Municipal Dumping Site in Nairobi, Kenya. Environmental Pollution and Impacts on Public Health (pp. 14). UNEP

KNBS. (2009), 2009 Population \& Housing Census Results. kenya: Minister of State for Planning, National Development and Vision 2030

Mangizvo V.R (2010), An overview of the management practices at solid waste disposal sites in African cities and towns. Journal of Sustainable Development in Africa 12 (7) 233239.

Mansaray, A., Ajiboye, J.O. and Audu, U.F. (1998), Environmental knowledge and attitudes of some Nigerian Secondary School Teachers. Environmental Education Research, 4, 329-339.

Nriagu, J. O. (1990), Global metal pollution. Poisoning the biosphere. Environment, 32(7),

7-33.

Olorunfemi, F.B, (2009), Living with Waste: Major Sources of Worries and Concerns about Landfills in Lagos Metropolis, Nigeria. Ethiopian Journal of Environmental Studies and Management 2 (2), 12-19.

Oyelola, O., Babatunde, A. I., and Odunlade, A. K. (2009), Health implications of solid waste disposal: case study of Olusosun dumpsite, Lagos, Nigeria. International Journal of Pure and Applied Sciences, 3(2), 1-8.

Prüss-Üstün, A. and Corvalán, C. (2006), Preventing disease through healthy environments Towards an estimate of the environmental burden of disease. Geneva: WHO 2006 publication

Rotich, K. H., Zhao, Y. and Dong, J. (2006), Municipal solid waste management challenges in the developing countries- Kenyan case study. Waste Management, 26, 92-100. 
Knowledge, Attitude and Perceptions of Village Residents on the Health Risk.................NJAGI et al.

Scholz, R. W. and Weber, O. (2001), levels in spinach (Amaranthus caudatus) and Judgements on Health Hazards to Soil lettuce (Lactuca sativa) grown in Maiduguri,

Contamination by Exposed and Non-Exposed Nigeria. Journal of Environmental Chemistry Residents. Zurich:ETHZurich,Umweltnatur und and Ecotoxicology, 3(10), 264-271.

Umweltsozialwissenschaften.

UN-HABITAT. (2008), The State of African

Cities. A Frame Work for Addressing Urban

Vrijheid, M. (2000), Health Effects of Residence near Hazardous Waste Landfill Sites: A Review Challenges in Africa: United Nations Human Settlement Programme.

of Epidemiologic Literature. Environmental Health Perspectives, 108 (1) 1-21

UNDP. (2006), Practical Action. Technology Zupancic, N. (1997), Lead pollution of ljubljanaChallenging Poverty: United Nation Zagreb roadside soils. Rudarsko-metalurski Development Programme Report. zbornik, 44(3-4), 169-185.

Uwah, E. I., Ndahi, N. P., Abdulrahman, F. I., and Ogugbuaja, V. O. (2011), Heavy metal 